\title{
Regulatory support of sustainable intermodal transport transit hub system development
}

\author{
Denis Vlasov ${ }^{1,2 a}$ \\ ${ }^{1}$ Moscow State University of Civil Engineering, 129337, Moscow, Russia \\ ${ }^{2}$ Genplan Institute of Moscow, 125047, Moscow, Russia
}

\begin{abstract}
The national urban development policy gives more and more attention to the most essential element of the City Transport Structure Planning - Intermodal Transport Transit Hubs. There is a significant number of ITTU project plans being developed in Moscow, Moscow region and different regions of the Russian Federation. While the regulatory framework for the development of documentation for ITTU territory planning is almost absent. This publication presents the author's point of view on the structure and composition of regulatory documentation for ITTU urban design. This article reports the results of the author's original scientific research on the development of ITTU systems.
\end{abstract}

\section{Introduction}

The transport infrastructure development is the priority direction of socio-economic urban planning in the Russian Federation. Modern, developed, efficient transport infrastructure is a key factor that ensures sustainable development of the whole country as well as of every region and municipality.

Recently, national urban planning policy pays much more attention to the development of various intermodal transport transit hubs (ITTH). A transport hub is the element of the city communication network that enables interaction between different modes of transport infrastructure as well as the interaction between city transport and serviced territory.

\section{Justification of regulatory documentation development}

Actually, ITTH is a miniature model of the urban transport infrastructure. But, unlike other elements of transport infrastructure, planning ITTH is not provided by any regulatory documentation.

The present work proposes the review of the main regulatory requirements for ITTH urban design taking in account that every element of transport infrastructure such as public transport, road network, pedestrian commuter etc., needs the same set of regulatory documents to be developed.

${ }^{a}$ Corresponding author: vlasych@mail.ru 
The urban planning Code of the Russian Federation [1] provides the development of regional standards for urban design. They must define «a set of indicators for minimum possible provision on the objects of regional importance". Besides, the Code provides the development of similar local standards.

Regional urban planning Codes can include the development of other types of regulatory documents. For example, the Urban Development Code of Moscow [2], in addition to Regional Standards, provides the development of Guidelines for Urban Design in the Moscow City.

Thus, in accordance with the current legislation, there is a growing need in development of several types of regulatory requirements and guidelines for the design of Transport Transit Hubs, such as:

- Regional Planning and Urban Design Standards;

- Guidance on Urban Design;

- Design Manual for Intermodal Transport Transit Hubs.

\section{ITTH regional planning and urban design standards}

The regional regulations on the development of Transport Transit Hubs System should contain the following sections:

- Glossary containing the definition of the key terms used in regulatory documents;

- ITTH Classification and

- Service Quality Indicators, comprising:

a. Transfer Guarantee Time.

Transfer Guarantee Time indicator allows objectively assess the passenger service quality. Paragraph 6.31 of the Federal "Guidance on Urban Planning..." [3] regulates that the transfer time at ITTH should not exceed 3 minutes.

b. Maximum transfer distance.

Foreign standards [4] tell that the maximum transit distance depends on the type of the change and averages:

- $150-160 \mathrm{~m}$ in case of change from land public transport modes to high-speed transport modes;

- 460-470 $\mathrm{m}$ in case of change from individual mode of transport to high-speed modes.

The current Russian Guidance [3] regulates that the walking distance from the stops of land public transport (p. 6.29) must average $500 \mathrm{~m}$.

c. The level of passenger service (Level of Service - LOS).

This indicator is not applied in national planning practice. In foreign practice it is an integrated index based on performance measure like intensity, speed, density, etc. of pedestrian traffic. LOS is calculated separately for each main element of the hub. The application of LOS indicator in the Russian practice is impeded because of a lack of representative surveys of national ITTHs.

d. Hierarchical access control.

Under the hierarchical access control it is defined the priority access system to the ITTH territory. In American practice (example the district of Columbia, for example) it is used the following hierarchy (starting from top level): "pedestrians - bicycles - road passenger transport - individual transport arriving for drop-off - private transport arriving at "Park and Ride". Such a hierarchy is associated with trips pattern to metropolitan stations in the Columbia District, where the ratio of road passenger transport arriving on transport transit hubs averages $15 \%$. For the realities of national life seems more appropriated to establish the following hierarchy: "land public transport - pedestrians - bicycles individual transport for passengers landing - individual transport for all types parking". 
One more alternative is the establishment of different hierarchies for the various planning zones of the city. Thus, the issues of the hierarchical access control become key ones to ensure rational and effective ITTH functioning and deserve the most careful study and discussion in the professional community.

\section{Instructions on urban design}

It seems appropriate to highlight the following main parts of the Guidance.

Introduction, to be devoted to the main issues of ITTH development.

It should be noted that the current practice [5-8] allows distinguishing three fundamentally different approaches to the urban design of transit hubs.

The first approach can be defined as a reconstructive-organizational development method. The essence of this method is the integrated local reconstruction of the ground level station areas only. In Russian planning practice, such solution is called "planar interchange node".

The second approach can be defined as a transport infrastructure priority development method. It suggests the exclusive construction of transport-purpose objects within the territory of the hub, mostly of "Park-and-Ride" facilities. At that, it is necessary to ensure spatial and functional relationship of all main elements of the site, especially between "Park-and-Ride" and landing platforms on high-speed stations [9]. In addition, the implementation of this method suggests also the realization totally or partially of the local reconstruction foreseen by the first method.

The third approach can be defined as a global construction method, as it involves the construction of a multifunctional interchange node on the territory of a transport transit terminal. The main aim of the interchange node is to provide comfortable transfer from one mode of transport to the other. Therefor it is suggested to build a single spatial ensemble that will unite under one roof all the main elements of a transport hub. Besides, in order to attract the investors for funding of the construction and for further development of the transit terminal it is suggested to give accommodation within its structure to residential, entertainment and retail areas intended for commercial leasing.

The implementation of any of these approaches should contribute to the realization of the main social domain of any kind of Transport Transit Hub, such as to ensure the most comfortable transfer conditions while changing transport mode with minimal time costs, including also the possibility for the provision of full range of associated passenger services [10]. The need of the transport transit hub reconstruction is determined by the level of its conformity to the norms and regulations of the Regional Standards and Guidance on Urban Design.

The above mentioned approaches can be realized separately or as the sequence of Transport Transit Hub reconstruction. As an example, let's consider the development of the Moscow ITTH "Vodny stadion".

On the photo (Figure 1) it is presented the current state of things on the ITTH. Even a cursory look at the photo allows to evaluate transfer conditions as not satisfactory, which effects the public service quality indicators, lowers comfort and safety of passengers stay on the ITTH territory, of the TPU, complicates functioning of all modes of transport. 


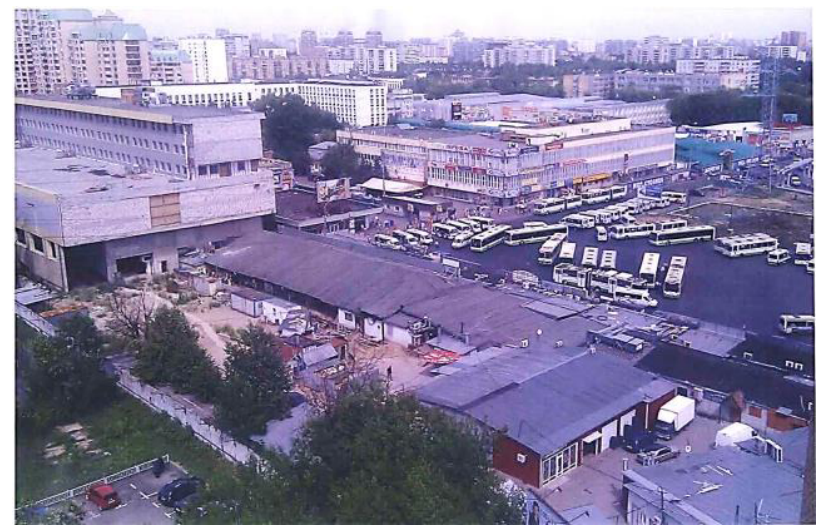

Fig. 1. The current state of the ITTH territory "Vodny stadion"

Figure 2 presents the composition parts of the project structure of the hub and proposals for a coherent evolutionary reconstruction of the ITTH territory.

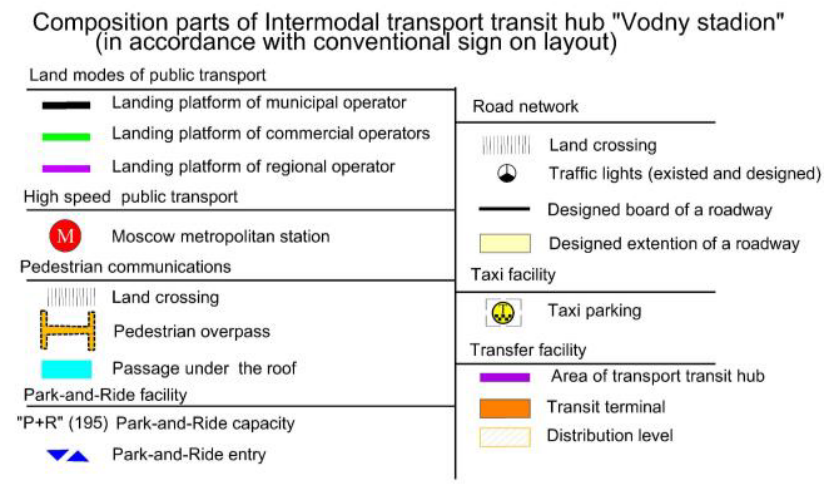

Fig. 2. Structure of ITTH «Vodny Stadion», Moscow, RF

Figure 3 shows the first simplest approach of planar reconstructive and organizational development of the ITTH territory.

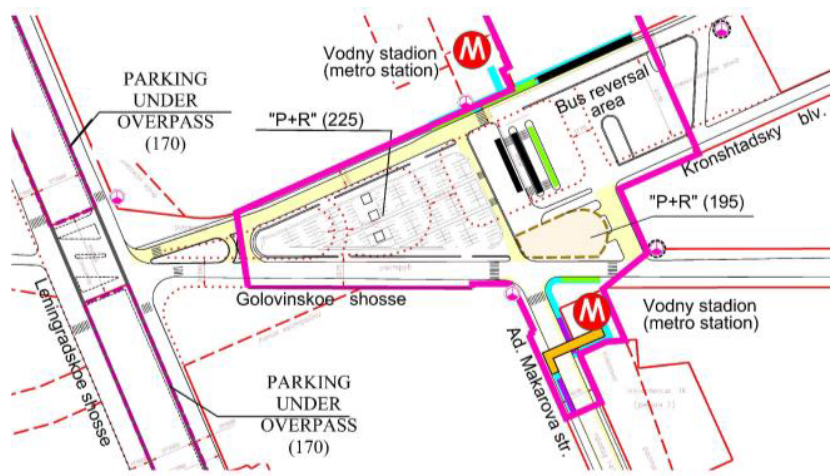

Fig. 3. ITTH «Vodny Stadion». The planar project in the ground level. 
In the course of evolutionary development of the site it is proposed the construction of local terminal only, to organize transfer process between land public and high-speed transport modes. It includes landing platform on the ground floor, distribution level on the first floor and pedestrian connection with the metro station (Figure 4).

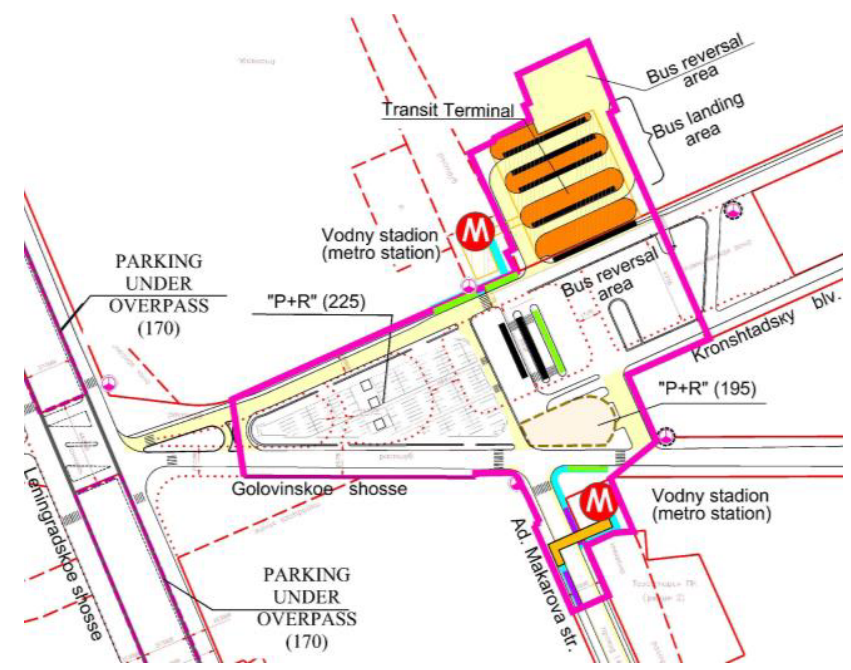

Fig. 4. ITTH «Vodny stadion». The project of compact transit terminal for land modes of public transport.

The large-scale level of the ITTH development includes the construction of huge multifunctional transit terminal with complex transport and public functions (Figure 5).

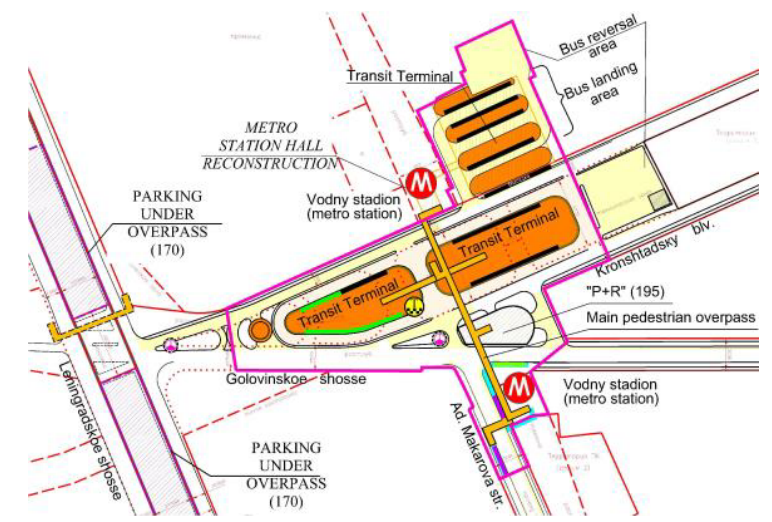

Fig. 5. ITTH «Vodny stadion». The project of huge complex transit terminal (superior development level)

Requirements for TPU. Every design solution for construction or reconstruction of any ITTH should follow three main principles, such as:

- ensuring passenger comfort and safety;

- multifunctionality, which requires compact placement of all ITTH facilities and elements using every possibility to combine different devices and facilities to ensure the best effectiveness;

- Complexity, which requires interconnection not only between all the elements of the site but also between the site and with the adjacent urban territories, with the account of their future sustainable development. 
In order to follow these principles, the author suggests to group the basic requirements for ITTH in three categories:

- transport requirements;

- urban development requirements (requirements for composition) and

- technologic requirements (requirements to ensure the efficiency of public transportation systems).

\section{ITTH design manual}

ITTH design manual should contain standards for calculation of all main areas of the hub, which include:

- communication zones;

- public transport areas and infrastructure;

- $\quad$ city road network and network of ITTH driveways;

- parking facilities.

All design activities must proceed in accordance with the evolution planned phases of the ITTH development process: for the period of the hub start-up; for the first state of development (5-7 years after the reconstruction); and for the estimated service life (2025 years). For sustainable operation, the ITTH should have $10-15 \%$ of reserve capacity of all standard elements [11].

\section{Conclusion}

The above shows the urgent need to development the regulatory base of ITTH design, reflecting their urban and socio-economic specificities, defining rules for their construction, reconstruction and operation. In this regard, the author considers it appropriate to develop and approbate the following regulatory documents:

- Regional standards for urban design of ITTH;

- Instructions for ITTH urban design;

- ITTH design manual;

- The calculation methodizes of the basic elements of ITTH.

Testing a complex normative documentation is available at transit nodes of Moscow and Moscow region.

Improving the regulatory framework and the functioning of ITTH requires performing complex of scientific-methodological research, which will justify quality indicators of ITTH transport services, allow the rationing of transit time, determine the minimum required composition of ITTH infrastructure elements.

\section{References}

1. The town-planning code of the Russian Federation from 29 dec. 2004, 190-FZ, http://base.garant.ru/12138258/\#ixzz41gbpboki (2015)

2. The Moscow town-planning code, No. 28 from 06.25.2008 (2015)

3. SP 42.13330.2011 the Federal Guidance on Urban and Rural Planning, http://www.minregion.ru/activities/771/tehreg/482/484/486/1045.html (2015)

4. Station Site and Access Planning Manual, Washington Metropolitan Area Transit Authority, https:// www.wmata.com/pdfs/ planning/ Station\%20Access/ SSAPM.pdf (2012) 
5. D.N. Vlasov, Transport transit hubs of the biggest city (on the example of Moscow city) (2009)

6. D.N. Vlasov, Scientific and methodological basis of transit transport hubs system development (on the example of Moscow agglomeration) (2013)

7. D.N. Vlasov, Academy. Architecture and construction, 3, 86-89 (2013)

8. D.N. Vlasov, Real estate: economy, management, 2, 55-58 (2011)

9. N.V. Danilina, Scientific-methodical bases of formation of system of "Park and ride" Parking areas in the largest cities: the example of the city of Moscow: the dissertation on candidate of technical sciences degree (2012)

10. N.V. Danilina, Internet-Vestnik VolgGASU, 2 (33), 29 (2014)

11. E.V. Sherbina, N.V. Danilina, D.N. Vlasov, Jour. of Applied Engineering Research, 1022, 43131-43138 (2015) 